To the Editor:

\section{Losing baby friendliness?}

In many societies traditionally mothers give prelacteal feeds (water, sugar-water, honey, tea, or animal milk) as the first feed instead of breastfeeds [1]. Prelacteal feeds are potentially harmful because they may introduce infection, sensitise the gut to foreign proteins, and delay the onset of lactation. Breastfeeding immediately after delivery enhances the mother and infant bonding, enforces uterine contractions and helps to prevent postpartum haemorrhage. The first breastfeed within one hour of delivery is one of the factors significantly associated with exclusive breastfeeding at discharge [2]. A delay in the onset of breastfeeding may lead to hypoglycaemia, hypothermia and acidosis, especially among high risk low birth weight infants [3].

In 1992 the WHO and Unicef launched the Baby Friendly Hospital Initiative (BFHI) in an effort to transform practices in maternity hospitals worldwide. The joint WHO/Unicef statement on 10 steps to successful breastfeeding has stressed that newborn infants should not be given any food or drink other than breast milk (unless medically indicated) and that mothers should be helped to start breastfeeding within $30 \mathrm{~min}$ of birth [4]. There is some evidence that the implementation of the "ten steps to successful breast feeding" of the BFHI will lead to an increase in breastfeeding [5] and its designation to hospitals has shown to be an effective strategy to increase breastfeeding rates of initiation [6]. In Sri Lanka, only a quarter of babies under 4 months are exclusively breastfed [7] although promotion of breastfeeding is not confined to the hospitals of the BFHI.

The duration of delay in initiation of breastfeeding has not been assessed in many Sri Lankan hospitals and a recent survey has shown that only $38 \%$ of neonates were breastfed within 30 min of delivery [8]. An audit conducted at Sri Jayewardenepura General Hospital (SJGH) revealed that only $23.5 \%(n=170)$ were breastfed within $30 \mathrm{~min}$ of delivery. The range in initiating breastfeeding was $7 \mathrm{~min}$ to $107 \mathrm{~min}$ (mean $45 \mathrm{~min}$, SD 20.1). None of the newborns received prelacteal feeds. A pilot study carried out in the operating theatre to assess the delay in initiation of breastfeeding after caesarian sections revealed that none of the newborns were breastfed within $30 \mathrm{~min}$ of delivery. The general reasons given for the delay in initiating breastfeeding were delayed suturing of episiotomies and lack of staff members.

The breastfeeding rate at SJGH is $100 \%$ in normal vaginal deliveries and none of the newborns received prelacteal feeds. This reflects success in conveying the importance of breastfeeding to the community and to health workers. However, 76.5\% had delayed initiation of breastfeeding, and there is room for further improvement here. In India, more than $70 \%$ of rural mothers use prelacteal feeds [9], and more than half of educated mothers from the upper socioeconomic classes in Bombay discard colostrum and use prelacteal feeds.
Data on initiation of breastfeeding varies in different countries. At Boston Medical Center this was 86.5\% [6]. In Bombay $68 \%$ were delayed for more than 24 hours [9] and in rural Egypt $31 \%$ for more than 72 hours [10]. In a district hospital in Bihar, India, only 14\% were breastfed within one hour of delivery [9], and in Sri Lanka's Ragama Teaching Hospital University Unit this was 38\% [8].

Action needs to be taken to improve the situation at SJGH. It is necessary to supervise the initiation of breastfeeding within 30 min of delivery, and causes for delay in initiation need to be addressed. Breastfeeding can be recommended while suturing episiotomies and before performing caesarian sections. This was successfully demonstrated at SJGH after the presentation of this breastfeeding audit. Studies and audits regarding initiation of breastfeeding within $30 \mathrm{~min}$ of delivery and assessment of other baby friendly steps should be carried out in all hospitals on a regular basis.

\section{Acknowledgements}

We are grateful to Research Medicinia Private Limited and labour room staff of SJGH for the valuable assistance.

\section{References}

1. Bradley JE, Meme J. Breastfeeding promotion in Kenya: changes in health worker knowledge, attitudes and practices, 1982-1989. Journal of Tropical Pediatrics 1992; 38: $228-34$.

2. Cattaneo A, Buzzetti R. Effect on rates of breast feeding of training for the baby friendly hospital initiative. British Medical Journal 2001; 323: 1358-62.

3. Anderson S, Shakya KN, Shrestha LN, Costello AM de L. Hypoglycaemia: a common problem among uncomplicated newborn infants in Nepal. Journal of Tropical Pediatrics 1993; 39: 273-7.

4. Salariya EM, Easton PM, Cater JI. Duration of breastfeeding after early initiation and frequent feeding. Lancet 1978; 2: 1141-3.

5. Evidence for the ten steps to successful breastfeeding. Geneva: WHO, 1998.

6. Philipp BL, Merewood A, Miller LW, Chawla N, MurphySmith MM, et al. Baby-friendly hospital initiative improves breastfeeding initiation rates in a US hospital setting. Pediatrics 2001; 108: 677-81.

7. Gunasekera DP, Gunasekera PC. In Sri Lanka only one quarter of babies under 4 months are exclusively breastfed. British Medical Journal 1998; 317: 1385.

8. Perera KPJ, Nellumdeniya U, Muthukumarana PSN, Ratnayake RAI, Wickramasinghe NK. Audit on breastfeeding in babies born at University Obstetric Unit, Teaching Hospital Ragama. Sri Lanka College of Paediatricians, Annual Scientific Congress, October 2003, Colombo, Sri Lanka, Abstract: page 45. 


\section{Research letters}

9. Prasad B, Costello AM de L. Impact and sustainability of a "baby friendly" health education intervention at a district hospital in Bihar, India. British Medical Journal 1995; 310: $621-3$.
10. Hakim I, El-Ashmawy I. Breast-feeding patterns in a rural village in Giza, Egypt. American Journal of Public Health 1992; 82: 731-2.

Pubudu de Silva, Medical Officer, Sampath Kusumsiri, Medical Officer and Rani Wasala, Paediatrician, Sri Jayewardenepura General Hospital, Nugegoda, Sri Lanka.

Correspondence: RW, Tel: +94 11 2778610, e-mail: <pubsy@sltnet.lk> (Competing interests: none declared). Received 25 March 2004 and revised version accepted 20 April 2004. 